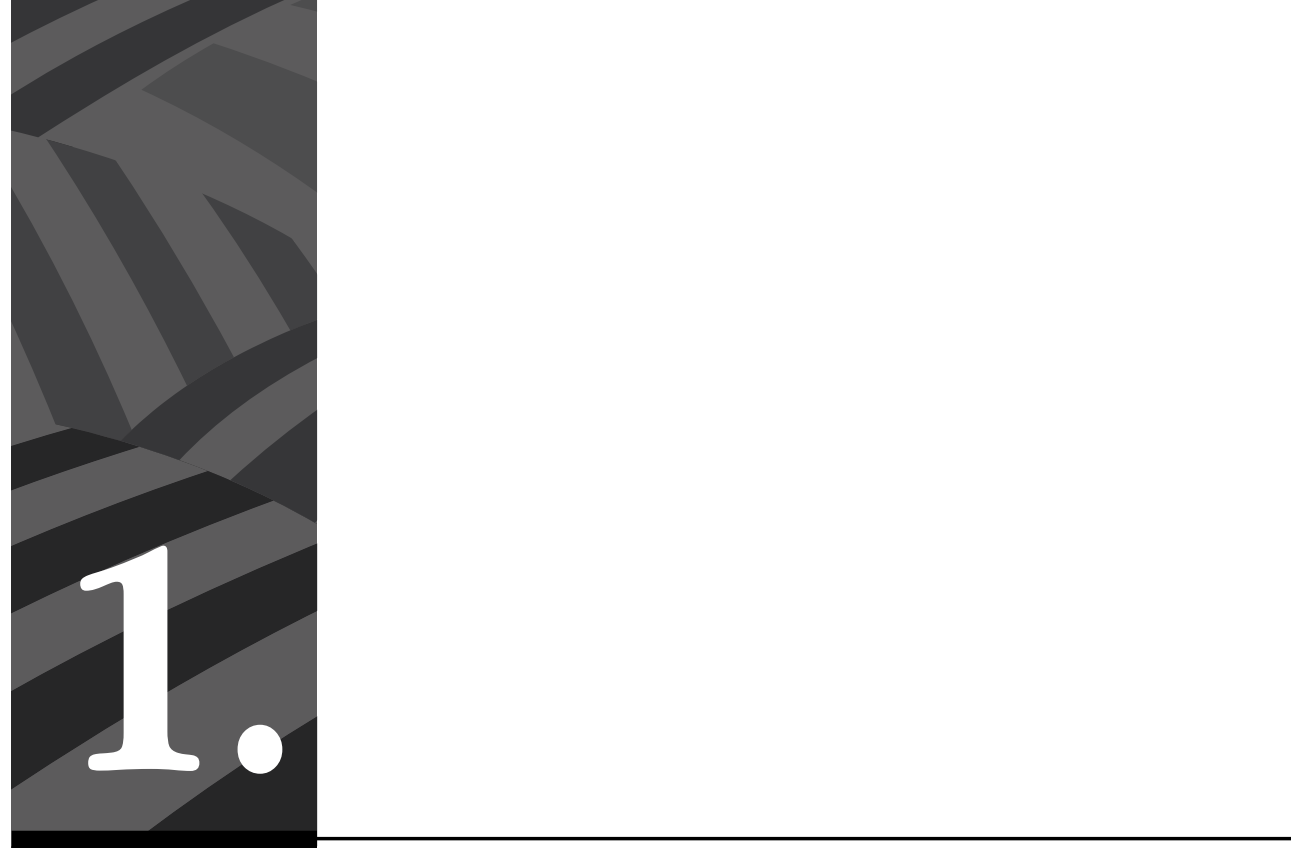

Cuatro años de camino en la implementación del Acuerdo Final de Paz entre el Gobierno y las Farc-EP 


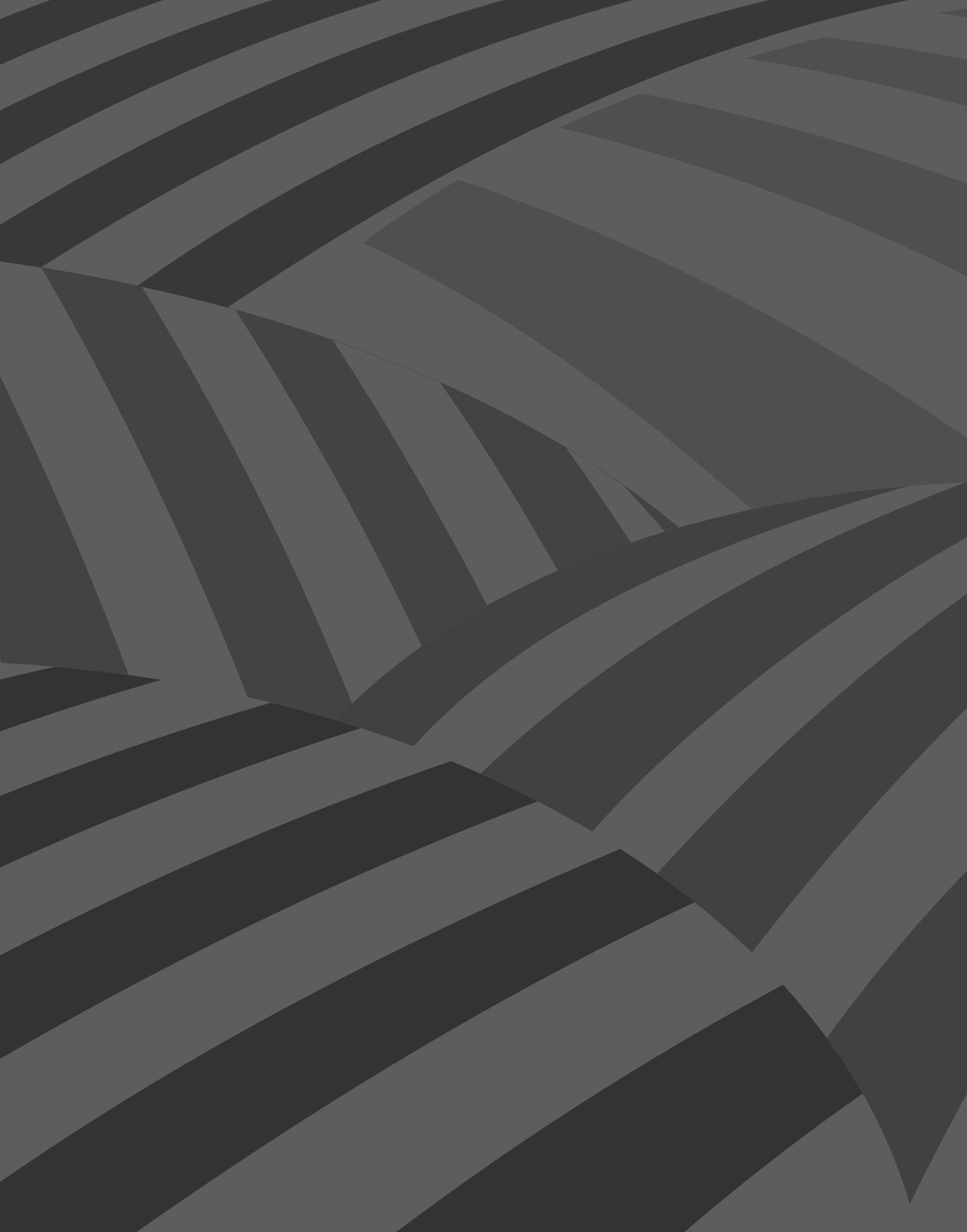




\section{Cuatro años de camino en la implementación del Acuerdo Final de Paz entre el Gobierno y las FARC-EP}

Por Consuelo Corredor ${ }^{*}$ y Clara Ramírez ${ }^{* *}$

DOI: https://doi.org/10.54118/controver.vi217.1235

Resumen: Durante décadas, Colombia estuvo en la agenda nacional e internacional de los estudios sobre violencia, por la prolongada duración del conflicto armado, por la diversidad de actores con roles y características diferentes, y especialmente por las serias consecuencias en cuanto a desplazamientos, desapariciones y asesinatos sufridos por amplios sectores de la población, así como por los graves efectos sobre el uso y apropiación de valiosos recursos vinculados a la tierra y a las actividades extractivas. Pasados algo más de cuatro años del proceso de implementación del Acuerdo Final de Paz entre el Gobierno y las Fuerzas Armadas Revolucionarias de ColombiaEjército del Pueblo (FARC-EP), que por el alcance de los compromisos y por los acuerdos inéditos en justicia transicional ha despertado un gran interés de académicos y políticos en el concierto internacional, en este artículo se presentan algunas reflexiones sobre el contexto en el que se ha desarrollado su implementación, las oportunidades que se han abierto, y los avances y retos que enfrenta, la mayoría de ellas derivadas de los informes realizados por los órganos dispuestos para el seguimiento y verificación de los compromisos adquiridos por las partes.

Palabras clave: conflicto armado, paz negociada, democracia, víctimas, tierras, desafíos, alertas.

\section{Four Years in the Way of Implementing the Final Agreement between the Colombia Government and the Farc-EP}

Abstract: For decades, Colombia was on the national and international agenda of studies on violence due to the prolonged duration of the armed conflict, due to the diversity of actors with different roles and characteristics, and especially due to the serious consequences of displacement,

* Investigadora del Cinep - Programa por la paz, del equipo de la Secretaría Técnica del Componente Internacional de Verificación de la Comisión de Seguimiento, Impulso y Verificación a la Implementación del Acuerdo Final (CSIVI), Colombia. Correo electrónico: ccorremar@yahoo.com

** Investigadora del Cinep - Programa por la paz, del equipo de la Secretaría Técnica del Componente Internacional de Verificación de la Comisión de Seguimiento, Impulso y Verificación a la Implementación del Acuerdo Final (CSIVI), Colombia. Correo electrónico: clara.ramirezgomez@gmail.com 
disappearances and murders suffered by broad sectors of the population, as well as the serious effects on the use and appropriation of valuable resources linked to land and extractive resources. After just over 4 years of implementation of the Agreement with the FARC-EP, Colombia awakens great academic and political interest in the international arena, due to the scope of the commitments and unpublished agreements on transitional justice and mechanisms for the sustainability of the achievements.

Keywords: armed conflict, peace negotiations, democracy, victims, land, challenges, alerts.

Cómo citar este artículo: Corredor, Consuelo y Ramírez, Clara (2021). Cuatro años de camino en la implementación del Acuerdo Final de Paz entre el Gobierno y las Farc-Ep. Una mirada desde América Latina. Revista Controversia, 217, 15-50.

Fecha de recepción: 28 de febrero de 2021

Fecha de aprobación: 31 de marzo de 2021

\section{Introducción}

$\mathrm{E}$ 1 Acuerdo firmado entre el Gobierno colombiano y las FARC-EP tiene como apuesta la TERMINACIÓN DEL CONFLICTO Y LA CONSTRUCCIÓN DE UNA PAZ ESTABle Y DURADERA, lo cual pasa por una serie de compromisos de corto, mediano y largo plazo que vayan allanando el camino para la reconciliación y brinden garantías de no repetición.

Durante cinco o seis décadas Colombia estuvo en la agenda nacional e internacional de los estudios sobre violencia por la prolongada duración del conflicto armado, por la diversidad de actores con roles y características diferentes $\mathrm{y}$, especialmente, por las serias consecuencias en materia de desplazamientos, desapariciones y asesinatos en amplios sectores de la población, así como por los graves efectos del uso y distribución de valiosos recursos vinculados a la tierra y a la actividad extractiva. Un prolongado conflicto armado que, sin embargo, no se reconoció durante algunos períodos como tal, lo cual fue un grave obstáculo para lograr una salida negociada, aunque hubo varios intentos que fracasaron (los procesos en la Uribe, en Tlaxcala, en el Caguán). 
Al inicio de la segunda década del presente siglo, se expidió la Ley de Víctimas (Ley 1448 de 2011), que significó un reconocimiento del conflicto armado, de su grave afectación y de la gran cantidad de víctimas, que hoy son estimadas en cerca de 9 millones y consideradas sujetos de reparación.

Para llegar a la firma del Acuerdo Final de Paz se estableció una agenda con un acuerdo marco general, logrado el 26 de agosto de 2012, y el compromiso explícito de terminar el conflicto, cuyo significado sintetizó con claridad Sergio Jaramillo (2018): (i) Compromiso de desarme y renuncia a las armas como forma de hacer política. (ii) No repetición, lo cual pasa por remover los factores que están en la base del mismo conflicto: fin de la violencia política; fin de la exclusión y marginación, en especial de las zonas más azotadas por el conflicto; restablecimiento y garantía de los derechos, y ampliación de la democracia; oportunidades de sustitución para los cultivos ilícitos. (iii) Reconocimiento de las víctimas mediante la verdad, justicia, reparación y garantías de no repetición. Señala Jaramillo: “Si se trataba de romper el ciclo de violencia y hacer justicia a tantas personas que sufrieron un daño irreparable en sus vidas, era necesario poner a las víctimas en el centro de la negociación” (2018, párr. 76), cualquiera que fuese el victimario.

Las experiencias internacionales sobre procesos de negociación para alcanzar la paz coinciden en identificar una serie de dificultades propias de la implementación de los compromisos adquiridos. En particular, estudios de Naciones Unidas y organizaciones internacionales encuentran serios obstáculos derivados de factores como la falta de claridad sobre lo que significa una paz consolidada, la metodología apropiada para el monitoreo, las dificultades en las evaluaciones comparativas, problemas de secuencia y transición, entre otros (Caplan, 2008). Colombia no ha sido la excepción. Desde la fase secreta de diálogo, pasando por la firma del Acuerdo Final, hasta el proceso de su implementación, las controversias y dinámicas del contexto nacional e internacional han sido muy cambiantes $\mathrm{y}$, en algunos casos, han tenido consecuencias serias sobre el cumplimiento de lo estipulado en los compromisos. 


\section{Importancia del contexto}

En todo proceso de negociación, una vez firmados los acuerdos, la implementación está sujeta a barreras estructurales, coyunturas electorales (locales, nacionales, internacionales), fuerzas opositoras legales e ilegales, imprevistos y fenómenos emergentes. Muestra de ello han sido los cambios en el contexto por la crisis sanitaria derivada de la Covid-19, así como el proceso y resultado electoral en EE. UU., dada la importante relación de este país con Colombia y con el Acuerdo de Paz, en especial en materia de narcotráfico y lucha contra las drogas ilícitas.

Todos estos factores hacen necesario un análisis del contexto y la consideración de sus efectos en el curso del proceso de implementación de los puntos acordados. De hecho, en lo corrido de los casi cinco años de implementación se ha puesto de presente, una vez más, la precariedad del Estado en las regiones del conflicto, su ineficacia y lenta respuesta a la cruda realidad, así como la importancia de la legitimidad y la confianza en la forma como se interviene en los territorios. Además, se confirma que los resultados de las acciones centralizadas, de carácter contrainsurgente y fragmentadas, no rinden los mejores resultados.

El Acuerdo de Paz firmado en Colombia en 2016 despierta un especial interés por el importante diagnóstico que logra. Reconoce las principales limitantes estructurales en el curso del desarrollo del país y, por supuesto, para alcanzar el propósito de construir una paz estable y duradera. Igualmente se hace explícita la responsabilidad estatal por acción u omisión en las enormes brechas de inequidad, y la desigualdad entre las personas y entre las regiones.

El contenido del Acuerdo y las oportunidades que abre para enfrentar dichas barreras, claramente respaldan lo afirmado anteriormente.

\subsection{Contenido y alcance del Acuerdo Final}

En el curso del proceso de negociación y en el texto mismo del Acuerdo se lograron identificar algunos de los problemas que la literatura sobre la 
violencia en Colombia ha establecido como los más explicativos en los diferentes conflictos y, en especial, respecto a los caminos que optaron por el uso de la vía armada como una forma de hacer política y que adoptaron la práctica de eliminar al adversario.

Un aspecto de la mayor importancia es el carácter integral de los seis puntos acordados y de muchas de las disposiciones que dan cuenta de la complejidad y multicausalidad del conflicto, y que comprometen los ámbitos político, económico, social, cultural, ambiental e institucional. Podría decirse que ello implica un mayor reto en la implementación, pero es imperativo si se pretende construir sobre bases sólidas una sociedad con justicia, equidad, mayor y mejor democracia. Se trata entonces de un Acuerdo que trasciende la paz negativa, entendida como la sola dejación de armas, para avanzar hacia una paz positiva que permita una transformación de los factores que están en el origen y en la dinámica de los conflictos. Su carácter integral también requiere de la incorporación de enfoques transversales, como son el de género, el étnico, el territorial y el de derechos humanos, como consta en los siguientes apartes del Acuerdo (Gobierno Nacional y FARC-EP, 2016).

\section{El enfoque de género reconoce}

la igualdad de derechos entre hombres y mujeres y las circunstancias especiales de cada uno, especialmente de las mujeres (...) para garantizar una igualdad efectiva se requiere adelantar medidas afirmativas que promuevan la igualdad, la participación de las mujeres y que respondan a los impactos desproporcionados que ha tenido el conflicto armado sobre ellas. (p. 173).

El enfoque étnico parte de enunciar un conjunto de principios del ordenamiento jurídico internacional y nacional, principalmente el de no regresividad, así como los siguientes:

A la libre determinación, la autonomía y el gobierno propio; a la participación, la consulta y el consentimiento previo libre e informado; a la identidad 
e integridad social, económica y cultural; a los derechos sobre sus tierras, territorios y recursos, que implican el reconocimiento de sus prácticas territoriales ancestrales; el derecho a la restitución y fortalecimiento de su territorialidad, los mecanismos vigentes para la protección y seguridad jurídica de las tierras y territorios ocupados o poseídos ancestral y/o tradicionalmente. (p. 186).

El enfoque territorial conduce a la integralidad de los compromisos establecidos, reconociendo su heterogeneidad y la importancia de la participación de los actores públicos, comunitarios y privados en el proceso, en particular de las mujeres y de los grupos étnicos, teniendo en el centro la reconciliación y la reparación a las víctimas del conflicto.

El enfoque territorial del Acuerdo supone reconocer y tener en cuenta las necesidades, características y particularidades económicas, culturales y sociales de los territorios y las comunidades, garantizando la sostenibilidad socioambiental; y procurar implementar las diferentes medidas de manera integral y coordinada, con la participación activa de la ciudadanía. La implementación se hará desde las regiones y territorios y con la participación de las autoridades territoriales y los diferentes sectores de la sociedad. (p. 6).

El objetivo final es la erradicación de la pobreza y la satisfacción plena de las necesidades de la ciudadanía de las zonas rurales, de manera que se logre en el menor plazo posible que los campesinos, las campesinas y las comunidades, incluidas las afrodescendientes e indígenas, ejerzan plenamente sus derechos y se alcance la convergencia entre la calidad de vida urbana y la calidad de vida rural, respetando el enfoque territorial, el enfoque de género y la diversidad étnica y cultural de las comunidades. (p. 11).

El enfoque de DD. HH. en el Acuerdo Final parte de una visión compartida entre las partes firmantes sobre la necesidad de reconocer y rechazar las graves violaciones a los derechos humanos; las infracciones al derecho internacional humanitario, producidas durante el conflicto armado, incluyendo los derechos económicos, sociales y culturales; y aquellos 
perpetrados contra los colectivos menos visibles como las mujeres, niños y niñas, población rural, comunidades étnicas y movimientos sociales. Todos los puntos del Acuerdo Final, y en especial el punto 5 sobre víctimas, deben contribuir a la protección y garantía de los DD. HH., así como a la promoción de una cultura política, democrática y participativa de respeto a estos. El Acuerdo reitera el compromiso de hacer efectivos los derechos contemplados en "la Constitución política de 1991, el Pacto de derechos civiles y políticos, el Pacto de derechos económicos, sociales y culturales, y los demás tratados Internacionales sobre derechos humanos ratificados por Colombia”. (p. 172).

\subsection{Oportunidades que se abren con el Acuerdo Final}

La gran apuesta por la terminación del conflicto y la construcción de una paz estable y duradera se encuentra en los objetivos, temas y subtemas de cada uno de los seis puntos del Acuerdo.

Es el caso del reconocimiento de la existencia de brechas urbano-rurales. De ahí resulta el énfasis en el enfoque territorial, que identifica el importante rol que ha tenido la tierra en los conflictos, con sus consecuencias de despojo y desplazamiento, y la permanente disputa por el control territorial con fines políticos y lucrativos a través de actividades lícitas, ilícitas y criminales.

De ello también resulta la importancia de los planes de desarrollo con enfoque territorial (PDET), como una estrategia de desarrollo para el cierre de brechas y la ampliación de la democracia, mediante la participación de las comunidades y el fortalecimiento institucional local, lo cual contribuye a la legitimidad y confianza en la institucionalidad. Igualmente, los Planes Nacionales para la Reforma Rural Integral (PNRRI) son una estrategia para restablecer y garantizar los derechos económicos, sociales y culturales; ampliar las oportunidades; y dar un mayor acceso a los bienes y servicios necesarios para una vida en dignidad. 
Es así como el punto 1 "Hacia un Nuevo Campo Colombiano: Reforma Rural Integral”, busca una transformación estructural del campo, lo cual pasa por el acceso y formalización de la tierra; por el cierre de brechas urbano-rurales y el desarrollo territorial, que contribuyan también a la ampliación de las oportunidades para la sustitución de cultivos ilícitos por parte de muchos campesinos que no tuvieron o no tienen una opción diferente de ingresos; por las condiciones de marginación y aislamiento del territorio en que se desenvuelven; al igual que por las medidas coercitivas impuestas por diferentes actores armados. En este marco, el punto 4 “Solución al Problema de las Drogas Ilícitas" reconoce los diversos factores que han dado lugar a las problemáticas derivadas de los cultivos ilícitos y a las políticas contra las drogas ilícitas y, por ello, establece un tratamiento diferenciado a los eslabones de la cadena de producción, comercialización y consumo. Su íntima relación con la reforma rural integral (RRI) es evidente, por lo cual se deben abordar de manera integral, para transformar las estructuras productivas mediante la sustitución de cultivos, con énfasis en el carácter voluntario, así como adelantar planes integrales de desarrollo alternativo en los que participen las comunidades. Los cultivos ilícitos tienen una racionalidad económica como fuente de generación de ingresos, dadas las difíciles situaciones de sobrevivencia en los territorios en que estos han prosperado, pero es la cadena del narcotráfico la que se apropia y beneficia del trabajo y de la tierra de los pequeños cultivadores. De ahí que el tratamiento de esta problemática respecto a los pequeños cultivadores no puede ser punitivo, pues su actividad es solo el inicio de la cadena del narcotráfico, el cual, además, contribuye mediante sus organizaciones criminales a nuevos ciclos de violencia, sin que se le pueda atribuir exclusivamente ni el origen ni la explicación única de los persistentes hechos violentos que a diario se registran. De ahí la importancia de discutir la tesis incompleta y simple a la que se recurre de manera permanente por parte del Gobierno, según la cual "el narcotráfico es la causa de todos los males".

Otro de los ejes del Acuerdo Final, respaldado por los análisis sobre la violencia en Colombia, es el reconocimiento de la estrechez del sistema 
político como una de las causas del conflicto armado, por lo cual la ampliación de la democracia y la participación política -aspecto contemplado en el punto 2 "Participación política: Apertura democrática para construir la paz" - son imperativos, en particular para los excombatientes firmantes del Acuerdo, pues es esa la razón principal del desarme y la negociación. Teniendo como referente la Constitución de 1991, se busca "canalizar institucionalmente los conflictos de la sociedad y de esta forma desterrar la violencia como recurso de lucha política y resolución de diferencias" (Secretaría Técnica del Componente de Verificación Internacional [sTCVI], 2019b, p. 32). Fue así como se concretaron tres objetivos centrales: acabar con el vínculo entre armas y política, ofrecer garantías para el ejercicio pleno de la participación ciudadana y la movilización social, y garantizar la transparencia y participación electoral, en especial en las regiones más afectadas por el conflicto armado, mediante la creación de 16 circunscripciones especiales transitorias de paz y la aprobación de una reforma política amplia y participativa.

La reincorporación de los excombatientes a la vida civil no es un fin en sí mismo, sino un medio de la mayor importancia para lograr su participación efectiva en la política (constitución en partido político) y brindarles oportunidades de inclusión sostenible en la vida social, económica y productiva (proyectos productivos, educación, salud), como consta en el numeral 3.2 del Acuerdo. Se trata de un proceso de corto, mediano y largo plazo, cuyo marco es la política pública de reincorporación (CONPES 31931 de 2018), que establece como requisito garantizar la protección y la seguridad a los excombatientes y sus familias, según lo aprobado en el numeral 3.4 del Acuerdo'.

1 “Acuerdo sobre garantías de seguridad y lucha contra las organizaciones y conductas criminales responsables de homicidios y masacres, que atentan contra defensores/ as de derechos humanos, movimientos sociales o movimientos políticos o que amenacen o atenten contra las personas que participen en la implementación de los acuerdos y la construcción de la paz, incluyendo las organizaciones criminales que hayan sido denominadas como sucesoras del paramilitarismo y sus redes de apoyo". 
Uno de los acuerdos más trascendentales es el de la justicia transicional que, si bien se ha dado en otras experiencias de negociación de conflictos (Yugoslavia, Sierra Leona, Ruanda, Camboya, entre otros), en Colombia integra las medidas de verdad, justicia, reparación y garantías de no repetición. De ahí que se hayan creado tres entidades dentro del Sistema Integral de Verdad, Justicia, Reparación y no Repetición (SIVJRNR): la Comisión para el Esclarecimiento de la Verdad, la Convivencia y la No Repetición (CEV); la Jurisdicción Especial para la Paz (JEP) y la Unidad de Búsqueda de Personas dadas por Desaparecidas (UBPD). Sus apuestas son de largo alcance: (i) la satisfacción de los derechos de las víctimas, mediante mecanismos de carácter judicial y extrajudicial; (ii) el esclarecimiento de lo sucedido a lo largo del conflicto, incluyendo sus múltiples causas, orígenes y sus efectos; (iii) el reconocimiento de responsabilidades frente a las víctimas, por parte de todos los participantes en el conflicto; (iv) la protección de la vida e integridad de las víctimas; (v) garantías para la no repetición de manera que ninguna persona sea revictimizada o esté en riesgo de serlo; (vi) la reconciliación para transitar caminos de civilidad y convivencia; y (vii) la construcción de una visión y compromisos compartidos sobre el respeto a los derechos humanos (Gobierno Nacional y Farc-EP, 2016, p. 162).

Finalmente, garantizar la implementación del Acuerdo en un horizonte de sostenibilidad requiere de la adopción de normas y leyes, de arreglos institucionales, así como de la articulación y coordinación de las instancias, medidas y herramientas previstas en el punto 6 "Implementación, verificación y refrendación", que comprometen al Gobierno, a la sociedad en general y a la cooperación internacional, entre las cuales está la Comisión de Seguimiento, Impulso y Verificación a la Implementación del Acuerdo Final (CSIVI).

Como se verá más adelante, la csivi es uno de los espacios más importantes de diálogo, concertación y seguimiento, de la que hacen parte representantes del Gobierno nacional y de las antiguas FARC-EP, con la partici- 
pación de Cuba y Noruega como países garantes. A su vez, el Plan Marco de Implementación de los acuerdos (PMI) y el Sistema Integrado de Información para el Posconflicto (SIIPO) son mecanismos establecidos para la planeación y seguimiento a los seis puntos del Acuerdo y sus componentes, y como tal ofrecen información oportuna, veraz y transparente sobre el proceso, las responsabilidades de las diferentes entidades y niveles de Gobierno, incluidos los recursos financieros destinados al PMI.

\section{Cómo va la implementación: avances y retos}

Un referente para analizar el estado de la implementación, después de cuatro años de firmado el Acuerdo, son sus propios objetivos.

Expertos en negociación de conflictos han señalado algunos problemas comunes a diferentes procesos de paz:

i) A pesar de la importancia y los hitos significativos que son los acuerdos de paz, los escenarios afectados por conflictos a menudo se caracterizan por problemas en un "compromiso creíble" (Joshi and Mason, 2011); ii) límites a las capacidades por parte de los responsables de la implementación (Peksen, Taydas y Drury, 2007) ; iii) la presencia de saboteadores del proceso (Stedman, 1997); y iv) élites renuentes a compartir el botín de poder (Kaldor, 2013; De Waal, 2015). Estos factores a menudo impiden significativamente el proceso de implementación. (Molloy, 2018, p. 8).

De hecho, en Colombia los cuatro problemas enunciados se han manifestado y han contribuido a que, a pesar de que se puedan señalar avances importantes, el ritmo en el cumplimiento de los compromisos haya sido lento ante recurrentes intentos de reformar lo acordado, incumplimientos de lo establecido, toma de decisiones que no corresponden al Acuerdo y, lo que es más grave, la persistencia de la violencia en muchos territorios, que se manifiesta en desplazamientos forzados, asesinatos selectivos de desmovilizados y de líderes sociales, y masacres, 
dando lugar a nuevos ciclos de violencia y de confrontación no solo con las fuerzas del Estado, sino entre diferentes actores ilegales armados en disputa por rentas de diversa índole. Esta es una situación que amenaza seriamente la construcción de una paz estable y duradera.

Desde la firma del Acuerdo se ha avanzado en la adopción de parte de la normatividad necesaria para la implementación de los seis puntos, por medio de reformas constitucionales, el procedimiento legislativo especial, el trámite legislativo ordinario y la producción de decretos y resoluciones. Pese a ello, de las 24 prioridades normativas definidas por el Acuerdo, 11 están pendientes en todo o en parte. Algunos de los faltantes son de gran importancia, como el referido al tratamiento penal diferencial para pequeños cultivadores, varias de las normas para la implementación de la RRI, el accidentado trámite legislativo de las circunscripciones transitorias especiales de paz que aún hoy están sin definirse, y otras relacionadas con la reforma política o la búsqueda de una mayor participación ciudadana ${ }^{2}$. Sin embargo, el Acuerdo goza hoy de una base constitucional y legal que brinda garantías para su implementación.

El compromiso central del Acuerdo, consistente en el cambio de las armas por la acción política, se inició con la dejación de armas por parte de algo más de 13000 excombatientes, su concentración geográfica y la conformación de un partido político por parte de la antigua guerrilla. La Misión de Verificación de las Naciones Unidas ha dado fe de ello. El proceso de reincorporación política, económica y social de los excombatientes se ha desarrollado con algunos altibajos. La inclusión económica mediante el desarrollo de proyectos productivos ha tenido el apoyo del Estado, de la cooperación internacional y de la autogestión de los propios excombatientes. Buena parte de las dificultades se relacionan con "falta de estrategias consolidadas de acompañamiento técnico” (STCVI, 2021, p. 8) y con el acceso a tierras, cuya solución no prevista por el Acuerdo

2 Para información más detallada Cfr. Octavo informe de verificación (STCVI, 2021, p. 245). 
ha sido buscada por el Gobierno, y se aprobó una ruta de acceso para lograrlo. La consolidación de los antiguos espacios territoriales de capacitación y reincorporación (AETCR) no está aún clara y persisten dificultades de acceso a bienes y servicios para los reincorporados y sus familias (Procuraduría General de la Nación [PGN], 2020, p. 196).

El punto más crítico en cuanto a reincorporación, que pone en peligro los resultados del propio Acuerdo y la búsqueda de la paz duradera, está relacionado con la garantía de protección a los excombatientes, a sus familias y comunidades, así como del partido político creado por los antiguos combatientes. Pese a que el Acuerdo establece medidas para garantizar su protección, la situación de inseguridad es muy alta, en especial en Cauca, Nariño, Antioquia, Caquetá y Meta, lo cual atenta no solo contra el derecho a la vida y la integridad de los excombatientes, sino que pone en riesgo también su reincorporación política, económica y social. El principal reto es lograr la implementación integral de las medidas e instancias creadas por el Acuerdo Final, lo cual pasa no solo por ajustar esquemas de protección y fortalecer las entidades encargadas de su implementación, sino por acelerar la investigación y judicialización de los responsables materiales e intelectuales (STCVI, 2021, p. 9).

En tercer término, es importante resaltar como avance la creación de las nuevas instituciones provenientes del Acuerdo Final, en particular de las entidades del SIVJRNR, así como otras relacionadas con el desarrollo de temas específicos del Acuerdo como la reincorporación.

\subsection{Los retos de la implementación}

Transcurridos más de cuatro años del tiempo previsto para la implementación del Acuerdo ${ }^{3}$, es posible hacer una primera evaluación de

3 El año final para el cumplimiento de los indicadores previstos en el PMI es 2031, es decir, 15 años luego de la firma, principalmente para medidas de la RRI y la reparación; muchos otros están planteados a ocho años, con finalización en 2026, como 
los efectos que este ha tenido sobre la sociedad colombiana, y plantear algunos retos en el corto y mediano plazo de cara a la construcción de una paz estable y duradera.

\subsubsection{La reforma integral del campo}

La Reforma Rural Integral tiene objetivos reformistas importantes: mejorar el acceso y la distribución de la tierra, integrar las regiones, contribuir a la erradicación de la pobreza, y varias medidas para promover una transformación estructural del campo. En un país con alta desigualdad en la distribución de la tierra y alto grado de informalidad en la tenencia de esta, las medidas acordadas son necesarias. Las dos propuestas centrales son: la entrega, en 12 años, de 3 millones de hectáreas a campesinos y campesinas sin tierra o con tierra insuficiente, y la formalización de 7 millones de hectáreas de pequeña y mediana propiedad rural.

Sin embargo, transcurrida la tercera parte del tiempo previsto, no ha habido un avance de importancia en la distribución de tierras ni en la formalización de estas. Aunque el Gobierno afirma avances en la conformación del Fondo de Tierras, hasta ahora este no ha sido instrumento de distribución. Es más, la Procuraduría General de la Nación (2021) afirma que aunque a fines de 2020 se encontraban más de 1 millón de hectáreas ingresadas al Fondo de Tierras, solamente están disponibles para ser distribuidas 96471,1 ha (2253 predios), lo cual es menos del $10 \%$ del total ingresado; la Agencia Nacional de Tierras (ANT) no ha identificado, para el $82 \%$ de las tierras del Fondo, si están ocupadas o disponibles para la distribución. Las hectáreas adjudicadas desde el inicio de la implementación hasta junio de 2020, llegaron a 30 318,6 (PGN, 2021, numerales 1 a 4), es decir que, de mantenerse ese ritmo de 8461 hectáreas/año, en los 12 años previstos solo se lograría el 3.3\% de la meta.

los relacionados con reforma política y la reincorporación; otros más tenían fechas de vencimiento en los primeros cinco años, es decir, debieran concluir este año. 
En cuanto a formalización, la información depurada de la PGN reporta una cifra de casi 1 millón de hectáreas entre 2017 y 2020, cifra inferior a la reportada por la ANT. De ellas, el 93,3\% corresponde a constitución y ampliación de resguardos indígenas, y en menor medida a titulación colectiva a comunidades negras (PGN, 2021, tabla 19). Los demás mecanismos de acceso a la tierra previstos por el Acuerdo ${ }^{4}$ han avanzado más lentamente. La implementación del Catastro Multipropósito, otra herramienta primordial para conocer los datos actualizados sobre predios formales e informales y la transformación del campo, apenas inicia su implementación en terreno, y se han priorizado 145 municipios (78 de ellos en zonas PDET).

Se concluye, entonces, que en los primeros cuatro años de implementación del Acuerdo, el acceso a la tierra y su formalización no han avanzado como se requeriría para una transformación rural, lo cual plantea el principal reto: un rápido avance en esta materia, de manera que los pobladores del campo puedan acceder a sus medios de vida en forma suficiente y segura. Las medidas de acompañamiento previstas por el Acuerdo, que implican proyectos productivos, acceso a riego, adecuación de tierras, entre otros, serán más importantes en la medida en que los procesos de adjudicación y formalización de tierras se aceleren. La vinculación de estos procesos con la transformación territorial prevista a través de los PDET, en 16 subregiones del país, es muy necesaria para que la reforma rural sea verdaderamente integral y efectiva. Lo mismo puede afirmarse sobre el papel que deben cumplir los PNRRI, que buscan disminuir las brechas entre la zona urbana y rural a través de políticas de alcance y diseño nacional que beneficien a las regiones más olvidadas. Al momento no ha concluido su formulación y solo cabe esperar que, en el próximo Plan Nacional de Desarrollo, estos sean tenidos en cuenta, pues en el diagnóstico de este pueden señalar algunas barreras y problemas que aquejan al desarrollo rural.

4 Entre ellos, los subsidios y los créditos para compra de tierras, que han tenido un desarrollo muy lento. 
Esta necesidad es aún mayor en la medida en que el panorama de pobreza y condiciones de vida no es esperanzador. Entre 2018 y 2019, según información del Departamento Administrativo Nacional de Estadística (DANE, 2020), la pobreza monetaria en Colombia aumentó y la pobreza rural lo hizo en mayor medida ${ }^{5}$. Los efectos económicos y sociales de la Covid-19 y su manejo son diversos, y han contribuido a un aumento nunca visto de la pobreza en el país. La fuerte caída de la actividad económica, con una tasa de $-6,8 \%$ en el PIB, casi sin precedentes en el país, y una difícil recuperación por cuanto la pandemia continúa y las medidas de mitigación diseñadas por el Gobierno no han sido suficientes para impedir el empobrecimiento de la población y no ofrecen un futuro esperanzador. Las cifras presentadas por el DANE (2020) muestran lo que algunos analistas han titulado "triste convergencia” (González, 2021), pues ante el aumento de las cifras de pobreza en las cabeceras municipales, donde pasó de $32,3 \%$ a 42, 4\%, y el descenso en las zonas rurales de 47,5\% a $42,9 \%$, las cifras prácticamente se igualaron, al tiempo que la pobreza extrema pasó de $19.3 \%$ a $18,2 \%$ en zonas rurales, manteniéndose por encima de la existente en cabeceras municipales (14,2\%). Aunque es claro que la pandemia ha golpeado con más fuerza las zonas urbanas, en especial los grandes conglomerados, no son claras las razones del descenso de la pobreza monetaria rural. El hecho de que el sector agropecuario haya sido el de mayor crecimiento durante la pandemia puede contribuir a la explicación de estas cifras. González (2021) menciona también, como razones de este comportamiento, el efecto de las ayudas gubernamentales extraordinarias entregadas durante la pandemia, que beneficiaron a muchos pobladores del campo ${ }^{6}$.

5 La pobreza monetaria rural pasó de $46 \%$ a $47,5 \%$ entre 2018 y 2019 , y la pobreza monetaria extrema de $16,2 \%$ a $19,3 \%$. En las cabeceras municipales la pobreza aumentó de $31,4 \%$ a $32,3 \%$ y la pobreza extrema de $5,8 \%$ a 6,8\% .

6 El DANE calcula el efecto de las ayudas extraordinarias en 5,0 puntos porcentuales de reducción de la pobreza extrema en el sector rural y 1,9 puntos en el sector urbano. En el caso de la pobreza total, las contribuciones de las ayudas extraordinarias alcanzan 4,2 puntos porcentuales en el sector rural y 1,6 puntos en el sector 
No es claro, sin embargo, si la implementación de los PDET ha tenido algún efecto en la reducción de la pobreza rural y en el mejoramiento de las condiciones de vida. El Gobierno, desde el Plan Nacional de Desarrollo y en cumplimiento de la política Paz con Legalidad, ha dado importancia a los PDET y ha centrado buena parte de sus intervenciones en los 170 municipios priorizados. Durante el gobierno de Duque se concluyó el proceso inicial de planeación de los PDET, con la aprobación de los 16 Planes de Acción para la Transformación Territorial (PATR) previstos como instrumento del desarrollo territorial. En ejecución de dichos planes se han realizado, a través de diferentes fuentes ${ }^{7}$, obras e inversiones de distintas dimensiones, centradas fundamentalmente en el mejoramiento de vías terciarias, necesarias en los territorios; algunas inversiones en mejoramiento de infraestructura educativa; y el desarrollo de proyectos productivos de acuerdo con las prioridades establecidas para las subregiones. Aunque el principal instrumento previsto por el Gobierno nacional para la planeación territorial es la Hoja de Ruta Única, hasta el 15 de mayo de 2021 solamente cuatro subregiones de las contempladas en los PDET (Catatumbo, sur de Bolívar, sur de Córdoba y Putumayo) contaban con dicho instrumento socializado. Esto implica que la ejecución de las obras en los territorios no ha correspondido necesariamente a la planeación territorial buscada. Si a esto se suma el considerable retraso en la expedición e implementación de los PNRRI, es claro que la implementación del Acuerdo en los territorios es aún incipiente y no cuenta todavía con todos los instrumentos en él previstos para su ejecución. Este retraso es grave, si se toma en consideración que el desarrollo territorial forma parte integral de la "presencia estatal", y que debe contribuir a solucionar demandas históricas y recientes de la población rural.

urbano. Sin dichas ayudas extraordinarias la pobreza rural habría sido de 45,8 y la urbana de 43,4\% (DANE, 2020).

7 Obras PDET (con recursos de los presupuestos nacional o territorial), obras financiadas con recursos del SGR (Ocad Paz, principalmente), obras por impuestos, así como recursos de cooperación internacional. 
En una coyuntura como la actual, la dinamización de economías rurales puede cumplir un papel importante. Vincular a la población en el desarrollo de las obras de infraestructura previstas por los PATR, por ejemplo, puede ser un factor multiplicador de la actividad económica local y proveedor de empleo e ingresos a un sector importante de la población pobre o empobrecida. Utilizar los recursos del adelanto del Sistema General de Regalías (SGR) puede contribuir a incrementar el dinamismo económico en los dos próximos años. Pero eso requiere de una voluntad clara de coordinación con las autoridades locales, de vinculación de la población de los territorios y de aplicación de los enfoques diferenciales.

\subsubsection{La ampliación de la democracia}

Contribuir a la ampliación y profundización de la democracia y la proscripción de la violencia como método de acción política es objetivo central del Acuerdo. Ello requiere garantizar el pluralismo, la promoción de la convivencia, el respeto por la oposición política, mayor transparencia y participación electoral, en fin, una mayor movilización y participación ciudadana en todos los asuntos públicos. Las garantías para ello son necesarias y constituyen parte central del cumplimiento del Acuerdo.

Pese a algunos avances importantes, como la aprobación y funcionamiento del Estatuto de la Oposición, los compromisos de ampliación de la democracia no presentan avances significativos. A casi cinco años de iniciada la implementación del Acuerdo, la normatividad pendiente da cuenta del bajo compromiso del Legislativo en la materia. Se destacan: i) los mecanismos de diálogo, vigilancia y control a las autoridades para prevenir el uso excesivo de la fuerza; ii) una ley estatutaria que otorgue garantías a la participación ciudadana y control social; iii) la reforma a la Ley 152 de 1994 para fortalecer la planeación democrática y participativa; y iv) Tramitar una Reforma Política que ajuste las recomendaciones de la Misión Electoral Especial (Instituto Kroc, 2020, pp. 51-55; STCVI, 2021b). 
Uno de los principales faltantes es la aprobación de las circunscripciones electorales transitorias de paz, que buscan que los territorios más afectados por el conflicto tengan representación en el Congreso, lo cual no fue posible para las elecciones de 2018 y se corre el riesgo que tampoco lo sea para las del 2022, si no se logran remover las numerosas trabas que se han interpuesto en su accidentada aprobación. Sorprende aún más que en la situación de descontento y de demandas sociales tan acentuadas, no haya esfuerzo alguno por sacar adelante todas estas iniciativas en pro de la ampliación de la democracia.

La participación ciudadana en los distintos ámbitos, necesaria para el avance del Acuerdo, se ha visto debilitada por la falta de garantías de seguridad y el consiguiente riesgo para los derechos a la vida y la integridad, situación reforzada por las restricciones propias de la pandemia. El retraso o la puesta en marcha incompleta de los instrumentos y estrategias definidas en el Acuerdo Final, como el Sistema Integral de Garantías de Seguridad para el Ejercicio de la Política (SISEP) y su Alta Instancia, así como la prioridad dada a herramientas instituidas por el Gobierno como el Plan de Acción Oportuna, en lugar de las creadas por el Acuerdo Final, no han permitido una adecuada operación de las estrategias ni resultados efectivos.

Como se señaló, hoy en día, el principal peligro para la implementación del Acuerdo es la afectación a la seguridad de excombatientes, líderes sociales y defensores de derechos humanos. En 2020 se presentaron 76 masacres con 292 víctimas (Alta Comisionada de las Naciones Unidas para los Derechos Humanos [ACNUDH], 2021), siendo el año con el registro más alto desde el 2014 (STCVI, 2021b). Incluso las mujeres que hacen parte de la Instancia Especial de Género, creada en el marco del Acuerdo, han sido víctimas de amenazas. Pese a las medidas tomadas por el Gobierno, los asesinatos continúan y las cifras se incrementan día a día. Si no se logra quebrar esta tendencia y garantizar en forma efectiva la seguridad en los distintos territorios, la implementación del Acuerdo está en juego. 
Ese quiebre implica otro enfoque y concepto de seguridad: el paso de la intervención de tipo contrainsurgente que por décadas prevaleció a lo largo del conflicto con las FARC-EP y demás grupos alzados en armas, a un concepto de seguridad humana. Instancias de verificación y algunos analistas coinciden en que la presencia muchas veces temporal de las fuerzas armadas no genera una mayor percepción de seguridad en las comunidades ni ha demostrado que, por sí sola, pueda resolver las amenazas cuando se reeditan violencias de distinto tipo en territorios tan importantes como Chocó, la costa Pacífica o el Catatumbo. Al contrario,

la consolidación de la presencia institucional, el fortalecimiento de los mecanismos locales de protección y solución de conflictos y la oferta de oportunidades económicas lícitas a las poblaciones vulnerables son la defensa más fuerte contra los grupos armados ilegales y las organizaciones criminales. (Misión de Verificación de Naciones Unidas, 2021, párr. 16).

La seguridad rural debe ser integral, diferenciada por regiones y centrada en garantizar el derecho a la vida. Debe tener en cuenta los nuevos escenarios de confrontación armada y los nuevos ciclos de violencia, buscando "recuperar la legitimidad y transparencia de las fuerzas armadas, cuyo mandato constitucional es proteger a la ciudadanía. La confianza de las comunidades en el ejército o la policía es un aspecto esencial de una política de seguridad eficaz” (García y Maya, 2021, párr. 7).

Por último, es necesario señalar que las movilizaciones sociales y las protestas ciudadanas de septiembre de 2020 y abril-mayo de 2021, con ocasión del Paro Nacional, han puesto de presente la evidente falta de garantías para la movilización y la protesta pacífica ${ }^{8}$, en las que persiste la criminalización y la estigmatización, pese a la Sentencia 7641 de 23 de septiembre de 2020 de la Corte Suprema de Justicia, que busca aumentar las garantías de protección al ciudadano y ordena al Gobierno establecer protocolos de participación.

8 Ver los informes quinto y sexto de 2019, séptimo y octavo de 2020 de la STCVI. 
Como se concluye en el Noveno informe de verificación de la implementación del Acuerdo Final de Paz en Colombia, de la STCvi (2021b, p. 72):

Estos pocos avances en materia de apertura democrática resultan más alarmantes si se tienen en cuenta los efectos de la pandemia en las prácticas e instituciones democráticas en todo el mundo. La pandemia puso un alto al ciclo de protestas que habían iniciado a finales de 2019, y como se ha observado, en la medida que se flexibilizan las medidas de confinamiento se han incrementado las movilizaciones. La pandemia sigue afectando el desarrollo normal de espacios de participación, sumado a la falta de garantías para las personas que asisten a estos espacios. Es importante resaltar que, para el caso colombiano, los efectos que han tenido las medidas para hacer frente a la pandemia, pese a que los impactos directos han sido limitados, preocupa que su costo sea mayor si se mantienen las restricciones y el uso excesivo de poderes de emergencia que afectan diferentes elementos básicos de un sistema democrático, tal como lo advierte el reporte de la Universidad de Gotemburgo (V-Dem Institute, 2021).

\subsubsection{Drogas y sustitución de cultivos ilícitos}

Este punto, cuarto del Acuerdo, está íntimamente ligado a la RRI. Desde la firma hay avances, pero pasados cuatro años:

Estos no han propiciado la transformación estructural que comprende el A.F., en la medida en que la intervención sigue priorizando la erradicación y la disminución de cultivos de uso ilícito como un factor de éxito en la política de drogas. Además, persisten situaciones que obstaculizan la plena implementación (...) como la insuficiencia de recursos, las dificultades administrativas, la insistencia en retomar la aspersión aérea con glifosato, las condiciones de inseguridad en los territorios afectados por cultivos de uso ilícito, que incluyen la presencia de Minas Antipersonal -MAP- y Municiones sin Explotar -MUSE- y su persistente uso por parte de organizaciones criminales. (STCVI, 2021, p. 10). 
Por ello, conviene insistir en que "una adecuada articulación del PNIS con una planeación territorial coherente con lo dispuesto en el A.F., es fundamental para progresar positivamente en el tema. Igualmente, es necesario el diseño y la puesta en marcha de modelos alternativos de sustitución” (STCVI, 2021b, p. 5).

Resulta indispensable hacer una evaluación del PNIS y de su articulación con otros programas, con el fin de establecer si es necesario reestructurar el programa, lo que implicaría hacer un nuevo costeo y una evaluación del alcance de este. Además, es importante impulsar medidas que permitan la articulación del PNIS con otros programas afines, así como con los PDET para ir más allá del cruce de iniciativas y apostar por la transformación productiva de los territorios focalizados. Asimismo, es prioritario que las comunidades participen en todas las etapas de ejecución del programa (STCVI, 2021b, p. 6).

En cuanto a la búsqueda de soluciones para la producción y consumo de narcóticos, buena parte de

las acciones adelantadas a la fecha se han centrado en el diseño y formulación de políticas, así como en la realización de estudios que no han potenciado una nueva mirada a este fenómeno en línea con los compromisos del A.F. y que parecen desarticuladas de los demás temas. Los avances son limitados en términos de impulsar acciones concretas que permitan dar una respuesta integral y efectiva a este fenómeno. (STCVI, 2021a, pp. 12-13).

\subsubsection{Las víctimas}

La garantía de los derechos de las víctimas a la verdad, justicia, reparación y no repetición enfrenta desafíos en la implementación del SIVJRNR, por lo cual ha estado en el centro del debate y ha generado controversias y obstáculos relacionadas con el cumplimiento del Acuerdo. De hecho, diversas fuerzas políticas contrarias a este, particularmente aquellas relacionadas con el partido político del Gobierno actual, han promovido 
esfuerzos para la modificación e incluso derogación de algunas disposiciones e instituciones que lo conforman.

Pese a ello, el SIVJRNR es uno de los componentes del Acuerdo que más ha reportado avances en su ejecución. La creación de tres entidades autónomas, independientes y con rango constitucional, permite desarrollar los mecanismos judiciales y extrajudiciales creados para el esclarecimiento de la verdad y el reconocimiento de responsabilidades de quienes participaron en el conflicto. Actualmente tienen sus marcos jurídicos consolidados, están en pleno funcionamiento y comienzan a producir resultados.

En el corto plazo, el componente de verdad enfrenta un desafío enorme: la Comisión de la Verdad debe entregar, al terminar este año, su informe final sobre la verdad de lo ocurrido en el conflicto armado. Varios son los problemas que ha enfrentado la Comisión: ataques a su legitimidad y puesta en duda de la idoneidad de sus miembros; dificultades de seguridad en los territorios, que afectan tanto a los funcionarios de la CEV como a las personas que aportan verdad; obstáculos para la entrega de información reservada, problemas que se ven incrementados por la coyuntura sanitaria, y que dificultan el desarrollo de actividades en los territorios.

El contexto electoral en el cual entregará la CEV su informe final es un reto difícil. Se corre el riesgo de que sus conclusiones sean instrumentalizadas por diversos actores, socavando las acciones de reconciliación y no repetición, disminuyendo las posibilidades de implementación inmediata. El mandato de la CEV es muy amplio, así como también el temor a la verdad en el país, y esta será un primer resultado del Acuerdo en esta materia. Una mejor recepción del trabajo de la CEV pasa por posibles acuerdos con diferentes sectores políticos de carácter nacional, de tal suerte que se allane el camino para futuras reformas estructurales en la institucionalidad, y con los mandatarios locales y los líderes/as en las regiones, con el propósito de obtener su compromiso político para 
recibir y dar espacio en sus territorios a la implementación de las recomendaciones, de modo que se evite la repetición de la violencia y las violaciones a los DD. HH. Es necesario que el informe cuente con la más amplia difusión y que la Comisión para el Esclarecimiento de la Verdad, la Convivencia y la no Repetición dispuesta por el Acuerdo Final, organizada por el Decreto 588 de 2017, empiece a operar tan pronto como la CEV concluya su mandato.

Por su parte, la JEP ha afrontado intentos continuos de modificación o derogación a través de distintos proyectos de ley presentados por el partido de Gobierno. Así mismo ha sufrido intentos de interferencias en su actuación, con declaraciones y afirmaciones que van en contra de la división de poderes, base de la estructura constitucional de la nación. Los avances de la JEP se observan en la presentación pública de la determinación de los hechos y conductas en los macrocasos 01 sobre toma de rehenes $y$ otras privaciones graves de la libertad y 03 sobre muertes ilegítimamente presentadas como bajas en combate por agentes del Estado. Estos resultados, y los consiguientes efectos, implican que la jurisdicción genere estrategias de comunicación que, a su vez, permitan a la ciudadanía conocer y comprender los contenidos y los impactos de sus hallazgos y decisiones. Esto aplica también en lo concerniente a facilitar la comprensión, por parte de la ciudadanía, de las respuestas de los comparecientes, en la perspectiva de consolidar las condiciones para la no repetición.

Igualmente, es importante avanzar en las determinaciones que se requieren para concretar el tipo de sanciones propias y los recursos financieros para implementarlas. Ante el interés de llevarlas a cabo en territorios donde se desarrollan los PDET, es importante examinar las condiciones de seguridad en las regiones, los grados de avance en la implementación del Acuerdo Final para apoyar los déficits, así como el compromiso institucional en el orden departamental y municipal, y los niveles de credibilidad y confianza de las comunidades en el proceso. 


\section{Alertas derivadas de la coyuntura}

\subsection{La integralidad del Acuerdo Final}

Si bien el Acuerdo Final está centrado en seis puntos, todos apuntan a la construcción de una paz estable y duradera, y por tanto debe considerarse como un conjunto integrado de compromisos que se complementan entre sí. No puede hablarse de desarrollo territorial si no se avanza decididamente en la distribución y formalización de la tierra, así como tampoco puede darse el cierre de brechas entre ciudad y campo, o entre regiones, sin desarrollo territorial. Si no hay catastro, riego, proyectos productivos, vías, vivienda, servicios, no hay acceso exitoso a las tierras. Tampoco puede hablarse de paz y de desarrollo territorial si no se integran en una nueva dinámica económica y productiva a los campesinos cultivadores de productos lícitos e ilícitos. Menos aún si no se cuenta con la participación de los pobladores, hombres, mujeres, campesinos, indígenas, afrocolombianos, y se garantiza la presencia estatal que implica dotación de bienes públicos rurales, acceso a educación y salud y, por supuesto, garantía a la vida, la libertad e integridad de las personas.

Con lo anterior claramente se aprecia el imperativo de la integralidad, aún más de cara a la sostenibilidad del proceso de paz que compromete Gobierno por lo menos los próximos diez años, según lo establecido, pero que sin duda tiene un horizonte de largo plazo dado su carácter transformador.

\subsection{La coyuntura}

A las dificultades propias de la implementación del Acuerdo se suman unos factores que configuran un complejo contexto en el que confluyen situaciones de orden interno y externo, que pueden poner en riesgo los logros alcanzados y los compromisos establecidos: 
- Persiste la oposición a algunos puntos del Acuerdo por parte de ciertos sectores políticos, del Gobierno y de la sociedad, que expresaron su rechazo en el plebiscito del 2 octubre de 2017, y que posiblemente lo reeditarán en las elecciones parlamentarias y presidenciales de 2022, proceso ya iniciado en forma temprana. Esto afectará la implementación del Acuerdo tanto en su dinámica como en su contenido, con propuestas sobre cambios sustanciales que podrían implicar el incumplimiento de los compromisos y pondrían en riesgo el espíritu mismo de este.

- Las voces que "exigen" modificar el Acuerdo en materia de participación política de los excombatientes, en razón al avance en los macrocasos que adelanta la JEP y anticipándose a las resoluciones de conclusiones, y luego a las sanciones que se impondrán por el Tribunal para la Paz, según lo acordado en materia de penas alternativas y restaurativas.

- Las demandas de las movilizaciones y protestas ciudadanas que fueron interrumpidas con la declaratoria de pandemia, pero que se han reanudado desde septiembre de 2020 y con mayor fuerza desde el 28 de abril de 2021, con nuevas demandas derivadas de las situaciones que la Covid-19 ha hecho visibles, y cuyo trámite por parte del Gobierno central no ha ido por la vía de afianzar la apertura democrática buscada con el Acuerdo Final. Estas movilizaciones serían, si existiera la voluntad política, una oportunidad irrenunciable para que las demandas de la población entren en diálogo constructivo con los compromisos del Acuerdo, pues muchos de los allí establecidos coadyuvarían a su solución.

- La falta de integración entre el tratamiento del narcotráfico y la política antidrogas con la RRI, pues las oportunidades duraderas de sustitución deben tener ese marco. Poner en la agenda esta reflexión es pertinente por las oportunidades que abre el nuevo gobierno de EE. UU., 
en cabeza de J. Biden. El Acuerdo Final, claramente, tiene una visión diferenciada entre los componentes de la cadena (cultivo, producción y comercialización) y pone el acento en la erradicación voluntaria.

La plena implementación del programa de sustitución de cultivos, así como de medidas que impulsen la solución al fenómeno de producción y comercialización, requiere enfatizar la integración del Programa Nacional Integral de Sustitución de Cultivos de Uso Ilícito -PNIS- con la Reforma Rural Integral y con las medidas relacionadas con las garantías de seguridad que contempla el Punto 3.4 del A.F. Esto impulsaría una transformación estructural de los territorios afectados por los cultivos de uso ilícito. (STCVI, 2021a, p. 10).

La expedición reciente del Decreto 380 de 2021 para retomar la aspersión aérea en la erradicación no voluntaria de cultivos, es una decisión que pone en riesgo la opción de erradicación voluntaria y la vinculación a oportunidades productivas para los campesinos.

- Las economías ilegales en busca de rentas derivadas principalmente de la extracción de recursos naturales tienen un rol muy grave en materia de los nuevos ciclos de violencia en algunos territorios. Si bien a ello se suma el accionar del narcotráfico, es errado considerar que este es el único factor explicativo de los nuevos ciclos de violencia, pues a ellos se suman quienes están en contra de la restitución de tierras, la defensa de los DD. HH., el cuidado del medio ambiente, entre otros.

- La pandemia, por su parte, también afecta la implementación del Acuerdo Final con dos caras: una negativa, que ante la difícil situación económica, laboral y fiscal, puede hacer más lentos los cambios y transformaciones en la calidad de vida de los sectores en mayor pobreza, y limitar los recursos fiscales destinados a su implementación; y una positiva, si las propuestas de recuperación y transformación pospandemia se ven como una oportunidad para dar un lugar 
de importancia a los territorios y a sus moradores, se promueven inversiones con efectos multiplicadores, y se toman las acciones necesarias para garantizar la seguridad y los compromisos adquiridos atendiendo a las especificidades y dinámicas territoriales.

\section{Instancias de diálogo y concertación}

Sin duda, los actores de primer orden son los firmantes del Acuerdo: el Gobierno, en representación del Estado colombiano, y las FARC-EP. El Acuerdo estableció diferentes instancias para la implementación de los compromisos, algunas de las cuales tienen prevista la participación de las dos partes, como es el caso del Consejo Nacional de Reincorporación (CNR), la CSIVI, la Comisión de Garantías de Seguridad (CGS), entre otras. Y, por supuesto, está comprometida la sociedad en su conjunto.

Quizá el principal mecanismo de verificación del Acuerdo sea la CSIVI, compuesta por representantes del Gobierno, las antiguas FARC y los países garantes: Cuba y Noruega. Está creada para garantizar la integridad de la implementación del Acuerdo, velar por el respeto a sus compromisos, y apoyar la continuidad y sostenibilidad del proceso ${ }^{9}$.

Sin embargo, la periodicidad y dinámica de la CsIVI se redujo al inicio del Gobierno actual, se reactivó desde fines de 2018 y se dio una modificación importante: "La secretaría técnica de la csivi quedó a cargo de la Consejería Presidencial para la Estabilización y la Consolidación ${ }^{10}$ y

9 La CSIVI se creó mediante Decreto 1995 de 2016. Su funcionamiento, previsto hasta enero de 2019, ha tenido tres prórrogas. La vigencia hasta enero de 2022 fue anunciada el 24 de diciembre de 2020, en el marco de una reunión de la csivi. El Decreto 1417 de 2018 actualizó su composición y funcionamiento, formalizó y reguló el funcionamiento del Componente Internacional de Verificación y dispuso el fortalecimiento de la interlocución entre la CsIVI y los componentes de acompañamiento y verificación internacional.

10 Por medio del Decreto 179 del 8 de febrero de 2019 se formalizó la Consejería Presidencial para la Estabilización y la Consolidación, antigua Alta Consejería Presidencial para el Posconflicto. 
no de la Oficina del Alto Comisionado para la Paz (OACP), otorgándole al Consejero para la Estabilización y la Consolidación la responsabilidad de centralizar y fortalecer la coordinación interinstitucional en la materia” (sTCVI, 2019a, p. 225).

A pesar de las dificultades y discontinuidades, la csivi desde su creación ha mostrado su importancia en el proceso de implementación y, por ello, preocupan sus fases de bajo dinamismo ${ }^{11}$. Igualmente está pendiente la descentralización prevista en el punto 6 del Acuerdo, pues es muy importante su funcionamiento en los territorios para facilitar el conocimiento de las dinámicas de implementación a través de la participación ciudadana y estimular el cumplimiento de los compromisos.

Hoy en día la CSIVI es una de las pocas instancias de encuentro entre las partes, pero ha perdido su rol de interlocución y búsqueda de solución a las controversias y diferencias sustantivas. De ahí la gran preocupación por su alcance, pues se ha centrado más en asuntos administrativos que en su función de mesa de diálogo y concertación política, como se esperaría y como es necesario para avanzar tanto en los compromisos como en la calidad de las intervenciones y actuaciones, pues no se puede prescindir de instancias y mecanismos para mantener el diálogo entre las partes, solucionar sus diferencias y controversias evitando que el elemento definitorio sean las relaciones de poder.

Y aquí nuevamente tiene un rol de la mayor importancia la comunidad y la verificación internacional, entre ellos los países garantes Cuba y Noruega, como canales que permitan escuchar voces, valoraciones,

11 Entre julio de 2018 y agosto de 2020, "la constancia y calidad de las reuniones ha disminuido. Las principales dificultades identificadas son: (i) "la falta de regularidad y periodicidad en el trabajo de la comisión” (CSIVI-FARC, 2019, p. 1); (ii) la debilidad de la csivi como un espacio para la resolución de controversias (Instituto Kroc, 2020); (iii) la celebración de reuniones 3x3 sin la presencia de todos los delegados del Gobierno. 
atender las alertas, los déficits y amenazas, así como estudiar las sugerencias para mejorar y ampliar las oportunidades que se derivan del proceso.

En experiencias anteriores de negociación en Colombia no se estableció un mecanismo de verificación robusto para el cumplimiento de los compromisos, basado en evidencias y asociado a la resolución de controversias. En el mejor de los casos, se obtuvo el apoyo de la comunidad internacional a importantes labores de acompañamiento y cooperación, mas no de verificación del cumplimiento (STCVI, 2018a, p. 199).

El seguimiento, el monitoreo y la verificación son importantes por su incidencia sobre el curso y la implementación de los procesos. Estos contribuyen a que las partes firmantes y la sociedad en general tengan elementos para valorar el cumplimiento de los compromisos, los faltantes, los riesgos, las amenazas y las oportunidades de mejoramiento. Igualmente, contribuyen a la rendición de cuentas a los países donantes y a la comunidad internacional que apoya el proceso ${ }^{12}$.

\section{Referencias}

Alta Comisionada de las Naciones Unidas para los Derechos Humanos [ACNUDH]. (2021). Informe de la Alta Comisionada de las Naciones Unidas para los Derechos Humanos sobre la situación de Derechos Humanos en Colombia durante el año 2020. Recuperado de https://www.hchr.org.co/index.

12 El Acuerdo Final de Paz firmado entre el Gobierno y las FARC estableció un componente internacional para la verificación de los compromisos adquiridos. En 2017 las partes designaron como Secretaría Técnica al CERAC y al CINEP-STCVI. En su primera fase de funcionamiento y durante 18 meses (noviembre de 2017 a mayo de 2019) dicha Secretaría produjo seis informes sobre la implementación de los seis puntos del Acuerdo y tres informes sobre la implementación del enfoque de género. En mayo de 2020 se inició la II fase, que irá hasta octubre de 2021, en la que ya se han publicado dos informes generales, dos sobre la implementación del enfoque de género y dos sobre el enfoque étnico. Todos los informes están disponibles en la página web tanto del CERAC como del CINEP. Las dos fases han sido posibles por la financiación del Fondo Multidonante de las Naciones Unidas para el Sostenimiento de la Paz. 
php/informes-y-documentos/informes-anuales/9547-informe-de-la-altacomisionada-de-las-naciones-unidas-para-los-derechos-humanos-sobre-lasituacion-de-derechos-humanos-en-colombia-durante-el-ano-2020

Caplan, Richard. (2010). Measuring Peace Consolidation and Supporting Transition. En Monitoring Peace Consolidation. Oxford: Institute for Applied International Studies, Norwegian Peacebuilding Centre \& UN Press.

Departamento Administrativo Nacional de Estadística [DANE]. (3 de mayo de 2019). Pobreza monetaria y multidimensional en Colombia 2019. Recuperado de https://www.dane.gov.co/index.php/ calendario/icalrepeat.detail/2019/05/03/4551/-/pobreza-monetariay-multidimensional-en-colombia

De Waal, Alex. (2015). Chapter 3: Armed Conflict and the Challenge of Hunger: Is an End in Sight? Recuperado de https://www.ifpri.org/sites/default/ files/ghi/2015/feature_3710.html

García, Andrés y Maya, Martha. (11 de enero de 2021). La paz: una oportunidad para 2021. Recuperado de https://razonpublica.com/ la-paz-una-oportunidad-2021/

Gobierno Nacional y FARC-EP. (2016). Acuerdo Final para la terminación del conflicto y la construcción de una paz estable y duradera. Recuperado de https://www.jep.gov.co/Documents/Acuerdo\%20Final/Acuerdo \%20 Final\%20Firmado.pdf

Gobierno Nacional y FARC-EP. (s.f.). 5. Acuerdo sobre las víctimas del conflicto "Sistema Integral de Verdad, Justicia, Reparación y No Repetición", incluyendo la Jurisdicción Especial para la Paz; y Compromiso sobre Derechos Humanos. Recuperado de http://es.presidencia.gov.co/Documents/Punto5.pdf

González, Jorge Iván. (7 de mayo de 2021). Triste convergencia. Recuperado de https://www.larepublica.co/analisis/jorge-ivan-gonzalez-506394/ triste-convergencia-3165595

Instituto Kroc. (2020). Cuarto informe: Tres años después de la firma del Acuerdo Final de Colombia: hacia la transformación territorial, Diciembre 2018 a noviembre 2019. Recuperado de https://peaceaccords.nd.edu/wp-content/ uploads/2020/09/091620-Reporte-4-Digital-.pdf 
Jaramillo, Sergio. (24 de julio de 2018). Lo que hizo posible la paz con las Farc. Recuperado de https://www.eltiempo.com/politica/proceso-de-paz/ sergio-jaramillo-explica-como-se-logro-la-paz-con-las-farc-247388

Joshi, Madhav and Mason, David. (2011). Civil war settlements, size of governing coalition, and durability of peace in post-civil war states. International Interactions, 34(4): 388-413. Recuperado de http://citeseerx.ist.psu. edu/viewdoc/download?doi $=10.1 \cdot 1.453 .4602 \&$ rep $=$ rep1\&type $=$ pdf

Kaldor, Mary. (2013). In Defence of New Wars. Stability. International Journal of Security and Development, 2(1), 1-16. Recuperado de http://doi. org/10.5334/sta.at

Misión de Verificación de la ONU en Colombia. (21 de enero de 2021). Declaración ante el Consejo de Seguridad de Carlos Ruiz Massieu, representante especial del Secretario General y jefe de la misión de verificación de las Naciones Unidas en Colombia. Recuperado de https://colombia.unmissions. org/declaraci \% C3 \% B3n-ante-el-consejo-de-seguridad-de-carlos-ruiz-massieu-representante-especial-del-2

Molloy, Sean. (2018). Assessing and Influencing Progress in Peace Processes Workshop Report. Edinburgh, UK.: The University of Edinburgh, Political Settlements Research Programme (PSRP). Recuperado de https://kroc. nd.edu/assets/288006/barcelona_report.pdf. [Traducción de la ST].

Procuraduría General de la Nación [PGN]. (Septiembre de 2020). Segundo informe al Congreso sobre el estado de Avance de la Implementación del Acuerdo de Paz. Recuperado de https://www.procuraduria.gov.co/portal/ media/file/Segundo \% 20Informe \% 20al \% 20Congreso \% 20Paz \% 20- \% 20 Procuradur \%C3\%ADa \%20General \%20de \%20la \%20Nación.pdf

Procuraduría General de la Nación. (7 de enero de 2021). Informe sobre el estado de avance de la implementación de las estrategias de acceso a tierras y uso del suelo rural contempladas en el Acuerdo de Paz. Recuperado de https://www.procuraduria.gov.co/portal/media/file/Informe $\% 20$ sobre $\% 20$ Acceso $\% 20$ y $\% 20$ Uso $\% 20$ de $\% 201$ a \% 20Tierra \% 20Def $\% 20$ 07_01_2021.pdf\#page42

Secretaría Técnica del Componente de Verificación Internacional CINEP/PPPCERAC. (Febrero de 2018a). Informe de verificación del primer año de implementación del Acuerdo Final de Paz en Colombia para los Verificadores 
Internacionales Felipe González y José Mujica (A.F. 6.3.2). Recuperado de https://www.verificacion.cerac.org.co/wp-content/uploads/2018/07/Primer-Informe-STCVI-Febrero-2018.pdf

Secretaría Técnica del Componente de Verificación Internacional CINEP/PPP-CERAC. (3 de septiembre de 2018b). Tercer informe de verificación de la implementación del Acuerdo Final de Paz en Colombia para los Verificadores Internacionales. Recuperado de https://www.cinep.org.co/Home2/component/ k2/624-tercer-informe-de-verificacion-de-la-implementacion-del-acuerdofinal-de-paz-en-colombia-para-los-verificadores-internacionales.html

Secretaría Técnica del Componente de Verificación Internacional CINEP/PPPCERAC. (4 de marzo de 2019a). Quinto informe de verificación de la implementación del Acuerdo Final de Paz en Colombia para los Verificadores Internacionales. Recuperado de https://cinep.org.co/Home2/component/ k2/670-quinto-informe-de-verificacion-de-la-implementacion-del-acuerdofinal-de-paz-en-colombia-para-los-verificadores-internacionales.html

Secretaría Técnica del Componente de Verificación Internacional CINEP/PPP-CERAC. (Septiembre de 2019b). Documento de balance de los primeros 30 meses de la implementación del Acuerdo Final. Recuperado de https://www. verificacion.cerac.org.co/wp-content/uploads/2019/09/Balance-30-mesesImplmentación-Acuerdo-de-Paz.pdf

Secretaría Técnica del Componente de Verificación Internacional CINEP/PPPCERAC. (Septiembre de 2020a). Séptimo informe de verificación de la implementación del Acuerdo Final de Paz en Colombia. Recuperado de https:// cinep.org.co/Home2/component/k2/828-septimo-informe-de-verificacionde-la-implementacion-del-acuerdo-final-de-paz-en-colombia.html

Secretaría Técnica del Componente de Verificación Internacional CINEP/PPPCERAC. (Noviembre de 2020b). Primer informe de verificación de la implementación del enfoque étnico en el Acuerdo Final de Paz en Colombia. Recuperado de https://cinep.org.co/Home2/component/k2/844-primerinforme-de-verificacion-de-la-implementacion-del-enfoque-etnico-en-elacuerdo-final-de-paz-en-colombia.html

Secretaría Técnica del Componente de Verificación Internacional CINEP/PPPCERAC. (Febrero de 2021a). Octavo informe de verificación de la implementación del Acuerdo Final de Paz en Colombia. Recuperado de https://www. 
cinep.org.co/Home2/component/k2/864-octavo-informe-de-verificacionde-la-implementacion-del-acuerdo-final-de-paz-en-colombia.html

Secretaría Técnica del Componente de Verificación Internacional CINEP/PPP-CERACSTCVI. (Febrero de 2021b). Documento sintético: Octavo informe de verificación de la implementación del Acuerdo Final de Paz en Colombia.:Recuperado de https://cinep.org.co/Home2/component/k2/864-octavo-informe-de-verificacion-de-la-implementacion-del-acuerdo-final-de-paz-en-colombia.html

Secretaría Técnica del Componente de Verificación Internacional CINEP/PPPCERAC. (Junio de 2021c). Noveno informe de verificación de la implementación del Acuerdo Final de Paz en Colombia. Recuperado de https://www. cinep.org.co/Home2/component/k2/895-noveno-informe-de-verificacionde-la-implementacion-del-acuerdo-final-de-paz-en-colombia.html

V-Dem Institute. (2021). Autocratization turns viral. Democracy Report 2021. Recuperado en: https://www.v-dem.net/files/25/DR\%202021.pdf 